\title{
Editorial
}

\section{EDITORIAL COMMENT: PSYCHOANALYSIS, CULTURE AND SOCIETY}

Psychoanalysis, Culture \& Society (2004) 9, 1-3. doi:10.1057/palgrave.pcs.2100013

s Editors we are proud to present to you the launch issue of
Psychoanalysis, Culture \& Society (PCS), formerly called The
Journal for the Psychoanalysis of Culture and Society (JPCS). With this issue, we celebrate a number of things: our move to Palgrave Macmillan Journals, our new editorial and international advisory boards of renowned academics and clinicians from around the world, and our new format. To create and celebrate this launch issue, we decided to ask members of our boards, including the board of the Association for the Psychoanalysis of Culture \& Society (APCS), to write about their views on the relation between the psychic and the social worlds. As you will see, several of the essays are position papers, some of which are quite personal. As a group, they more than fulfill the mission of the journal, which is to embrace all schools of psychoanalysis and to focus our efforts on the way in which psychoanalysis can help us not only to understand the cultural problems that beset us but also to effect positive social change.

In keeping with our wish to publish clinical as well as academic psychoanalytic papers, this issue contains Elisabeth Young-Bruehl's (chair of the board of APCS and member of the international advisory board of the journal) conceptualization of the variety of forms of child maltreatment and how they intertwine. Her case example shows the limitations of the usual nosological categories of child abuse. Kareen Ror Malone (an associate editor of PCS) and Shannon D. Kelly critique, from a Lacanian perspective, a recently published relational clinical paper on the psychic effects of changes in family structure. Their larger purpose is to caution against the importation into clinical work of ideological frameworks, even when those frameworks are "alternative." Also bridging the clinical and the academic worlds is the paper by Lynne Layton (editor of PCS), which elaborates a relational view of unconscious processes and argues that the kinds of psychic damage with which both clinical work and psycho-social theory contend emerge not from the givens of subject formation (from which derives 
"common human unhappiness") but rather from interactions with hostile and hierarchical environments, the sources of "neurotic misery." Muriel Dimen (international advisory board) writes something of a manifesto for a relational postmodern clinical and theoretical psychoanalytic practice that synthesizes Freud and Marx; while Dimen's piece points to the existence of such a clinical practice; Anthony Elliott (international advisory board) pits a postmodern against a modernist psychoanalytic episteme and controversially argues that clinical work has not kept up with postmodern advances in analytic social theory. It is hoped that this kind of strong position paper will stimulate lively debate in future issues of the journal.

Paul Hoggett (international advisory board member) writes a deeply personal autobiography of his engagement, over several decades, with psychoanalysis and politics - the strange attractors of his title. Hoggett's psycho-social framework is largely Kleinian, a perspective also elaborated by Karl Figlio (international advisory board). Figlio, drawing on Klein, Bion, and Habermas, contests some of the basic assumptions of liberal democracies, especially the assumption of freely consenting, equal relationships; contrasting what he calls "projective communication" with "informative communication," Figlio examines the way that the anxieties inherent to collective action always threaten to result in a narcissistic retreat from relationship. The rich vein of social criticism enabled by Klein's clinical theory is also explored by Simon Clarke's (editor of PCS) analysis of the Kleinian concept "envy." Clarke's essay is what PCS refers to as a "key concept" piece, in which the author examines the sociocultural potential opened up by a particular analytic concept.

Three Lacanian papers posit an equally informative position on social, political and cultural phenomena. Paul Verhaeghe (international advisory board member) and Stijn Vanheule explore the relationship between psychoanalysis, science and creativity. Verhaeghe and Vanheule argue that a major challenge for psychoanalysis lies in the development of its own methodological strategies for empirical research. Method, on one hand, has to be compatible with and acceptable to other disciplines; on the other hand, it should still retain the richness of the traditional clinical method. Henry Krips' (associate editor) paper attempts to formulate a psycho-politics which grounds its practices in "Real" political struggles. Lacan's theory of the four discourses and the recent work of Slavoj Zizek point to interesting and new approaches to the integration of psychoanalytic theory and politics, argues Krips - but they throw up more questions than they answer. Using the work of Saul Alinsky, Krips formulates an alternative psycho-politics in which he argues that publicity provides the power that multiplies the effect of individual political acts into a social effect. Robert Samuels (associate editor and associate executive director of APCS) takes us closer to the university in an exploration of how we might use psychoanalytic cultural criticism to teach about social change in writing courses. 
Finally, Barry Richards' (international advisory board) position paper demonstrates well, and actively and enthusiastically supports, the aims of this journal. Richards argues that psychoanalysis should be firmly established in universities. Not only does the university provide a place for sustained self-reflection on our research and teaching, as critical theorists have argued for many years, but it also maximizes the chances for psychoanalysis to make a distinctive contribution to facilitating positive social change. Psychoanalysis has a unique contribution to make to changing our understanding of the relationship between reason and passion. This is a key issue for academia, this journal, and for social and political change in the 21st century.

Future editions of the journal will continue to highlight the way in which psychoanalytic ideas and concepts, together with new and original methodologies, can help us understand the complex inter-relationship between the psyche and the social world at both an individual and group level. Issues such as racism, sexism, class inequality and identity are inextricably bound up in both a political economy and a psychodynamic process, in irrational fears and social constructions. Psychoanalysis, Culture \& Society has at the heart of its ethos a commitment to explore and lay bare these processes.

The editors would like to thank all the contributors to this journal, the referees and readers, and everyone involved in the production of this launch issue. In particular, we would like to thank Rachel Young, Di Owen and Jane Torr at Palgrave Macmillan Journals for smoothing the transition between publishers and for supporting the elaboration and dissemination of psychoanalytic thinking. We would also like to thank our universities for their support and in particular the Faculty of Humanities, Languages and Social Science at the University of the West of England for providing editorial space and time for the journal.

Finally, with this issue Mark Bracher, founding editor of JPCS and co-founder of APCS steps down from his editorial duties and becomes Founding Editor. Mark single-handedly kept the journal alive for years and built it up from strength to strength, making it a place where all psychoanalytic points of view were welcome. Mark's conviction that psychoanalysis is an important tool in work for social change imbued and will continue to imbue the journal with purpose. Everyone at PCS and APCS is grateful to Mark for his years of hard work finding excellent material, copy-editing it, and establishing JPCS/PCS as a premier psycho-social journal.

Simon Clarke and Lynne Layton University of the West of England and Harvard University. 